EPJ Web of Conferences 59, 07002 (2013)

DOI: $10.1051 /$ epjconf/20135907002

(C) Owned by the authors, published by EDP Sciences, 2013

\title{
Recent progress in the development of pulse compression gratings
}

\author{
S. Hocquet ${ }^{1}$, J. Néauport ${ }^{1, a}$ and N. Bonod ${ }^{2}$ \\ 1 CEA CESTA, 33114 Le Barp, France \\ 2 Institut Fresnel, CNRS UMR 6133, Aix-Marseille universités, École Centrale Marseille, \\ Domaine Universitaire de Saint-Jérôme, 13397 Marseille, France
}

\begin{abstract}
The PETAL facility uses chirped pulse amplification (CPA) technique. This system needs large pulse compression gratings that request damage threshold better than $4 \mathrm{~J} / \mathrm{cm}^{2}$ in normal beam at $1.053 \mu \mathrm{m}$ for $500 \mathrm{fs}$ pulses. In this paper, we will show recent grating designs with either multilayer dielectrics or hybrid metal-dielectric structures. We have shown in previous works that damage threshold is driven by the enhancement of the near electric field inside the pillars of the grating. This was evidenced from a macroscopic point of view by means of laser damage testing. We will show that damage morphology during damage initiation at the scale of the grating groove is also consistent with this electric field dependence.
\end{abstract}

\section{INTRODUCTION}

The PETAL facility [1] laser beam, currently under construction on the Megajoule Laser (LMJ), in France [2] consists in the combination of a high intensity multi-Petawatt laser line synchronized with the nanosecond LMJ laser beams. The PETAL short pulse line is designed to deliver short pulses (500 fs-10 ps) with ultra high power beam of several petawatts. PETAL is based on chirped pulse amplification (CPA) method [3] in combination with Optical Parametric Amplification (OPA) in the front end. It can deliver $3.6 \mathrm{~kJ}$ of energy with pulse duration down to $500 \mathrm{fs}$ at the wavelength of $1.053 \mu \mathrm{m}$.

The compressor of the PETAL facility is a two stages compressor [4]. A first compressor is used to reduce the pulse duration from a few nanoseconds to some hundred picoseconds. A second compressor under vacuum is then used to reduce the pulse duration from few hundred picoseconds to the $500 \mathrm{fs}$ pulse final duration. The compressors, as many other similar systems, are made of large diffraction gratings used in reflection to compress the laser pulses. Moreover, a beam size of $37 \times 37 \mathrm{~cm}^{2}$ with up to $3.6 \mathrm{~kJ}$ with imposes a damage threshold of $4 \mathrm{~J} / \mathrm{cm}^{2}$ normal beam for $500 \mathrm{fs}$ pulses on the last grating of the vacuum compressor (taking into account beam modulations).

After compression, the laser beam is conveyed under vacuum to the target chamber by a set of large transport mirrors. These mirrors are used at an incidence close to $45^{\circ}$ in $\mathrm{TE}$ or TM polarization depending on their location. Laser induced damage threshold of all the large optics operating under vacuum is a real challenge. We detail in this paper our efforts in the field of pulse compression gratings only. The main specifications of these gratings are detailed below:

- $1780 \mathrm{1} / \mathrm{mm}$, incidence of $77.2^{\circ}$, wavelength of $1.053 \mu \mathrm{m}$, bandwidth of $6 \mathrm{~nm}$

- Size of $420 \times 450 \mathrm{~mm}^{2}$, thickness of $43 \mathrm{~mm}$

- TE polarization,

- $-1 \mathrm{R}$ diffracted wavefront quality better than $\lambda / 5$, diffraction efficiency: $95 \%$.

- Damage threshold of more than $4 \mathrm{~J} / \mathrm{cm}^{2}$ beam normal at $500 \mathrm{fs}$.

\footnotetext{
ae-mail: jerome.neauport@projet-lmj.org
}

This is an Open Access article distributed under the terms of the Creative Commons Attribution License 2.0, which permits unrestricted use, distribution, and reproduction in any medium, provided the original work is properly cited. 


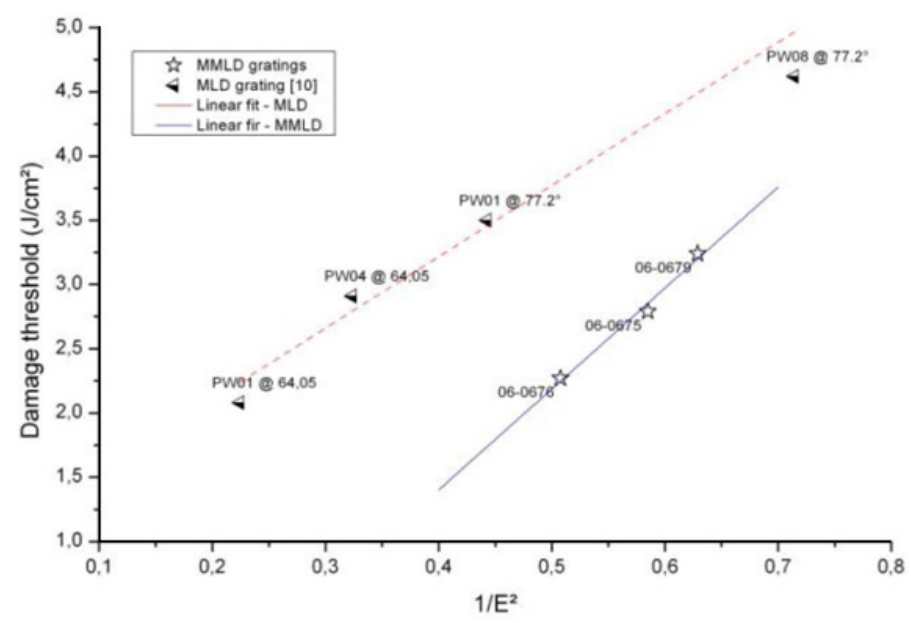

Figure 1. Damage performance at $1.053 \mu \mathrm{m}$, TE polarization, and $500 \mathrm{fs}$ versus $1 / \mathrm{E}^{2}$ maximum on different MMLD grating samples [11] and MLD grating samples [10] tested at $77.2^{\circ}$.

\section{MULTIDIELECTRIC PULSE COMPRESSION GRATING DAMAGE MECHANISMS}

Gold gratings were used to compress laser beams, but their damage thresholds are limited to 0.5 to $1 \mathrm{~J} / \mathrm{cm}^{2}$ at $500 \mathrm{fs}$ normal beam at the wavelength of $1.053 \mu \mathrm{m}$ [5]. To overcome this limitation, MLD gratings were introduced by LLNL [6]. A multilayer dielectric (MLD) grating consists of a multidielectric mirror with a grating engraved in its top layer leading to a significant improvement in the laser induced damage (LID) threshold thanks to the suppression of metal in the structure [7]. Since then, efforts were made in the last decade to enhance damage performances of MLD grating and to understand physical mechanism leading to laser induced damage (LID). First assumptions on the role of the electric field enhancement on the LID were advanced by Britten et al [8]. It was also shown that thin pillar tends to reduce the E field enhancement while thick pillar enhance it. More recently our group performed a complete study of the impact of the electric field enhancement on the LID by manufacturing and damage testing $1780 \mathrm{l} / \mathrm{mm}$ MLD gratings at an incidence of $77.2^{\circ}$, in TE polarization, at the wavelength of $1.053 \mu \mathrm{m}, 500 \mathrm{fs}$ pulse duration. Samples tested differ by the grating profile in terms of pillar height and duty cycle. Damage testing was performed on the DERIC facility in S/1 mode, $10 \mathrm{~Hz}$, with 100 sites tested and 100 shots per site [9]. During this study, we evidenced that damage threshold is proportional to $1 /|\mathrm{E}|^{2}$ in the grating material, where $|\mathrm{E}|$ is the norm of the electric field in the solid material normalized by the norm of the electric field of the incoming wave [9]. This result was also observed on Mixed Metal Dielectric (MMLD) gratings that is basically a mirror constituted of a gold layer covered by some pairs of dielectrics with a low index top layer engraved [10]. This principle allows a reduction of the stack thickness and the suppression of crazing that sometimes occurs under vacuum [11]. Moreover such a design is also of interest in the context of large spectral bandwidth. While testing these MMLD gratings, we also observed a LID proportional to $1 /|\mathrm{E}|^{2}[11,12]$. These two results are summarized on Fig. 1.

If in both cases, electric field dependence is linear, the value of LID differs, driven by the material properties of the dielectric coating which in this case was performed by two different suppliers for MLD and MMLD gratings. It is also interesting to notice that when optimizing a pulse compression grating for high damage threshold, ones have to make a compromise between diffraction efficiency and electric field enhancement reduction. This is illustrated on Fig. 2 for a 1780 1/mm MLD grating at $77.2^{\circ}$, TE.

When such MLD gratings are manufactured and tested, LID and diffraction efficiency are in good agreement with simulation presented above as depicted on Fig. 3. 

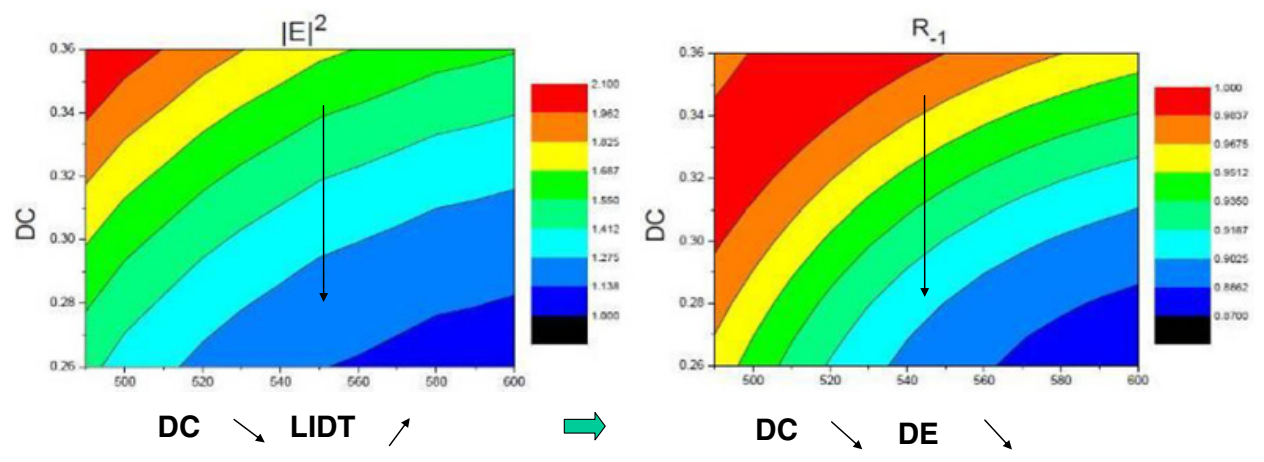

Figure 2. Evolution of $-1 \mathrm{R}$ diffraction efficiency (right) and $|\mathrm{E}|^{2}$ (left) with duty cycle (DC) and pillar height of the $17801 / \mathrm{mm}, 77.2^{\circ}$, TE pol grating.

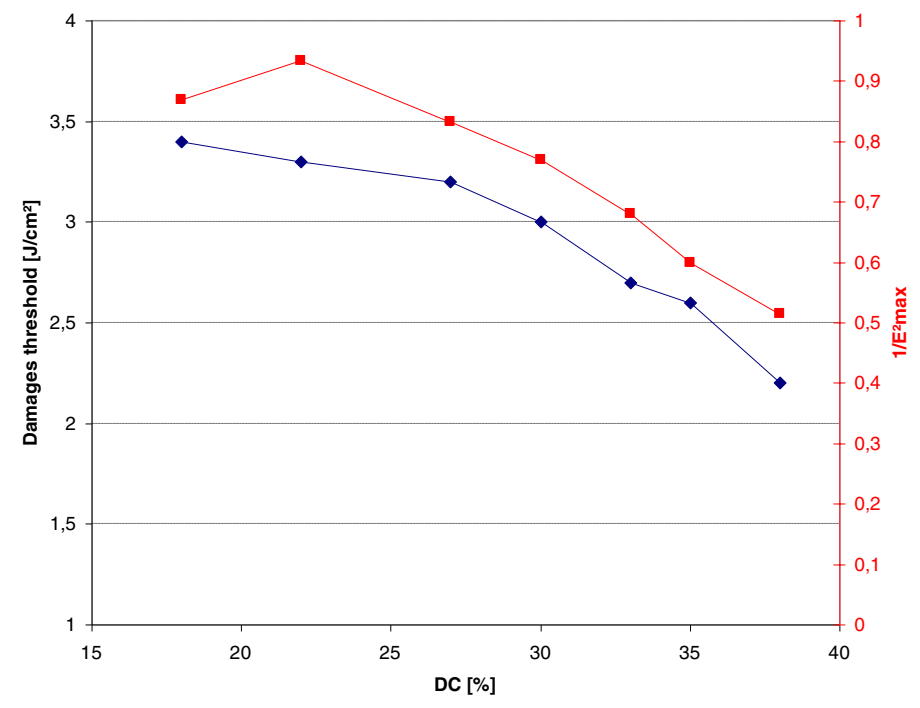

Figure 3. Evolution of LID and DE for a $17801 / \mathrm{mm} 77.2^{\circ}$, TE pol MLD grating with different DC.

Note that LID is not linked to diffraction efficiency (DE) and that the highest LID is obtained for a $90 \%$ DE grating with a duty cycle of $18 \%$ for this peculiar design.

We also investigated damage initiation on pulse compression grating at a microscopic scale. For this purpose, a 1780 1/mm grating was damage tested on the DERIC facility and observed by Scanning Electron Microscopy (SEM). Figure 4 presents the SEM image obtained.

We can see that grating pillars damage on the side opposite to the incoming wave with good concordance with electric field repartition. A perpendicular periodic structure can also be observed. Such periodic called ripple was observed on various materials. Ripples are likely to be induced by interferences between the incoming wave and a scattered wave due to surface roughness [14]. Grating pillar roughness is rather high due to the manufacturing process. In order to assess this hypothesis, we damage tested a TE-optimized MLD grating in both TE and TM polarization. The interest of such an experiment is that in TM polarization, pillar roughness is almost not seen by the incoming wave and ripples should then disappear. It is exactly what is seen during experiments. Moreover we notice that 

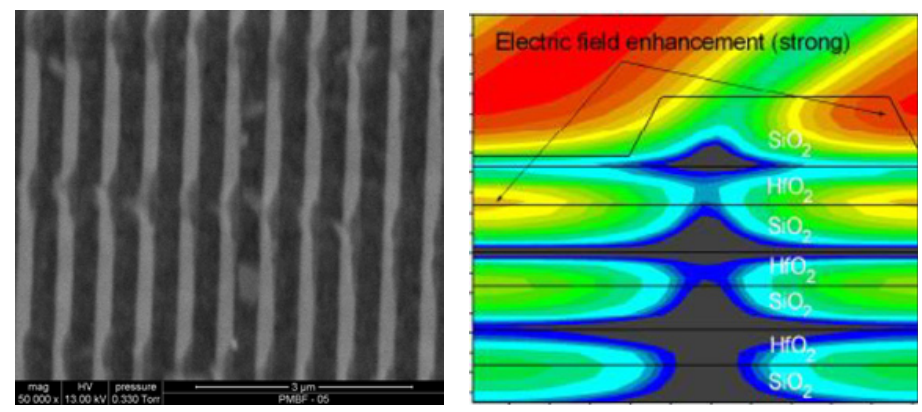

Figure 4. Damage initiation on a $17801 / \mathrm{mm}$ grating, TE pol (left). Electric field repartition in the MLD grating (right). Incoming wave is coming from the left side in both cases.

LID in TM is increased by a factor notably superior to the $\left[\left.\mathrm{E}\right|^{2}\right.$ ratio. This evidence that ripples limit the damage performances of MLD grating in TE. It then paves the way to the development of TM MLD gratings.

This work is being performed under the auspices of the Conseil Régional d'Aquitaine, of the French Ministry of Research and of the European Union and with the technical supports of the Institut Lasers et Plasmas. We would like to thank people at HORIBA Jobin Yvon and Plymouth Grating Lab for grating manufacturing.

\section{References}

[1] N. Blanchot et al., Plasma Phys. Control. Fusion 50, 124045 (2008)

[2] ML. André, Solid state lasers for application to inertial confinement fusion, Second annual international conference. Proc SPIE 3047, 38 (1996)

[3] D. Strickland and G. Mourou, Opt. Commun. 56, 219-221 (1985)

[4] N. Blanchot, G. Marre, J. Neauport, C. Rouyer, S. Montant, A. Cotel, C. Leblanc, C. Sauteret, Applied Optics 45, 6013 (2006)

[5] B. C. Stuart et al, J. Opt. Soc. Am. B 13, 459 (1996)

[6] M. D. Perry, R. D. Boyd, J. A. Britten, B. W. Shore, C. Shannon and L. Li, Opt. Lett. 20, 940-942 (1995)

[7] C. P. J. Barty et al., Nuclear Fusion 44, 12 (2004)

[8] J. Britten et al., Boulder damage symposium, Proc SPIE 5273 (2004)

[9] J. Neauport, E. Lavastre, G. Razé, G. Dupuy, N. Bonod, M. Balas, G. de Villele, J. Flamand, S. Kaladgew, and F. Desserouer, Opt. Express 15, 12508-12522 (2007)

[10] N. Bonod, J. Neauport, Optics Communication, Vol 260, Issue 2, 649-655 (2006)

[11] H. Leplan, B. Geenen, J. Y. Robic, and Y. Pauleau, J. Appl. Phys. 78, 962 (1995)

[12] Neauport J., Bonod N., Hocquet S., Palmier S., and Dupuy G., Opt. Express 18, no 23 (2010)

[13] J. F. Young, J. S. Preston, H. M. van Driel, and J. E. Sipe, Phys. Rev. B 27, 1155 (1983)

[14] S. Hocquet, J. Neauport and N. Bonod, Applied Physics Letters 99, 061101 (2011) 